\title{
Systemic Long-Distance Signaling and Communication Between Rootstock and Scion in Grafted Vegetables
}

\author{
Xiaohong Lu, Wenqian Liu, Tao Wang, Jiali Zhang, Xiaojun Li and Wenna Zhang* \\ Beijing Key Laboratory of Growth and Developmental Regulation for Protected Vegetable Crops, China Agricultural \\ University, Beijing, China
}

\section{OPEN ACCESS}

Edited by:

Rosario Paolo Mauro,

University of Catania, Italy

Reviewed by:

Andreas Wilhelm Ebert,

World Vegetable Center, Taiwan

Fei Cheng,

Huazhong Agricultural University,

China

*Correspondence:

Wenna Zhang

zhangwenna@cau.edu.cn;

wennafhxy@163.com

Specialty section:

This article was submitted to Crop and Product Physiology, a section of the journal

Frontiers in Plant Science

Received: 18 February 2020

Accepted: 27 March 2020

Published: 05 May 2020

Citation:

Lu X, Liu W, Wang T, Zhang J, LiX and Zhang W (2020) Systemic

Long-Distance Signaling and Communication Between

Rootstock and Scion in Grafted Vegetables. Front. Plant Sci. 11:460.

doi: $10.3389 /$ fp/s.2020.00460
Grafting is widely used in fruit, vegetable, and flower propagation to improve biotic and abiotic stress resistance, yield, and quality. At present, the systemic changes caused by grafting, as well as the mechanisms and effects of long-distance signal transport between rootstock and scion have mainly been investigated in model plants (Arabidopsis thaliana and Nicotiana benthamiana). However, these aspects of grafting vary when different plant materials are grafted, so the study of model plants provides only a theoretical basis and reference for the related research of grafted vegetables. The dearth of knowledge about the transport of signaling molecules in grafted vegetables is inconsistent with the rapid development of large-scale vegetable production, highlighting the need to study the mechanisms regulating the rootstock-scion interaction and long-distance transport. The rapid development of molecular biotechnology and "omics" approaches will allow researchers to unravel the physiological and molecular mechanisms involved in the rootstock-scion interaction in vegetables. We summarize recent progress in the study of the physiological aspects (e.g., hormones and nutrients) of the response in grafted vegetables and focus in particular on long-distance molecular signaling (e.g., RNA and proteins). This review provides a theoretical basis for studies of the rootstock-scion interaction in grafted vegetables, as well as provide guidance for rootstock breeding and selection to meet specific demands for efficient vegetable production.

Keywords: hormone transport, long-distance signaling, phloem transport, protein transport, RNA transport, systemic signaling, vegetable grafting, xylem transport

\section{INTRODUCTION}

Grafting is one of the main means of asexual reproduction of horticultural crops such as fruit trees, vegetables, and flowers. It is used extensively to ameliorate the biotic stress, such as that caused by fungi and viruses, of crops (Cohen et al., 2000, 2005, 2007; Ioannou, 2001; Nisini et al., 2002), enhance abiotic stress tolerance to extreme temperatures and other environmental factors

Abbreviations: IAA, indole acetic acid (an auxin); CL, carlactone; ABA, abscisic acid; GA, gibberellic acid; CK, cytokinins; ACC, 1-aminocyclopropanecarboxylic acid; JA, jasmonic acid; SL, strigolactone; $t Z$, trans-zeatin; $t Z R$, trans-zeatin riboside; DEGs, differentially expressed genes; DEMs, differentially expressed miRNAs; DAPs, differentially accumulated proteins. 
(Zhou et al., 2007). Grafting can also induce alterations in fruit traits, such as size (Garcia-Lozano et al., 2020), rind thickness (Fredes et al., 2017), and flesh firmness (Bertucci et al., 2018).

The mechanisms regulating the rootstock-scion interaction can affect plant growth and development, adaptation to environmental conditions, and physiological and biochemical characteristics. For example, grafting can result in an improvement of vegetable quality by increasing the synthesis of endogenous hormones and the acquisition and transport of mineral nutrients (Lee et al., 2010; Wang Q. et al., 2017); it can also alter secondary metabolites, creating novel flavors (Lee et al., 2010; Kakizaki et al., 2017), and the concentrations of fruit metabolites such as lycopene, carotenoids, and amino acids (Lee et al., 1996; Davis et al., 2008).

Recent advances in molecular biotechnology and bioinformatics techniques have stimulated research into the dual interaction between rootstocks and scions (Warschefsky et al., 2016). In vegetables, grafting and "omics" analysis have been integrated to examine the transport of mRNAs, small RNAs [specifically small interfering RNAs (siRNAs)], and proteins (Kim et al., 2001; Haywood et al., 2005; Zhang K. et al., 2014). In addition, grafting, especially in horticultural plant propagation, is an important method and a means to study basic processes such as flowering mechanisms, and long-distance conduction in plants (Turnbull, 2010; Goldschmidt, 2014). In these experiments, different grafting combinations of mutant and wild-type materials are subjected to some treatment, and the substance of interest (e.g., plant hormone, mRNA, protein) is detected in the rootstock and scion.

Here, we summarize research over the past two decades on grafting-induced changes in and transport of endogenous substances, including phytohormones, mineral elements, RNAs, and proteins, in vegetables. We pay particular attention to the potential molecular mechanisms underlying long-distance trafficking of RNAs and proteins between rootstocks and scions. We supplement our discussion with information on signaling transport verified in other plants and in nongrafting experiments. Our purpose is to provide a perspective from which to unravel the mechanisms underlying longdistance signaling between vegetable rootstocks and scions, and to provide a reference for the selection of vegetable grafting combinations.

\section{PHYSIOLOGICAL ASPECTS OF THE ROOTSTOCK-SCION INTERACTION IN GRAFTED VEGETABLES}

\section{Phytohormones}

Current research on phytohormones is mainly focused on physiological function, biosynthesis, and metabolism, and signal perception and transduction ( $\mathrm{Li}$ and Li, 2019). Arabidopsis thaliana (Arabidopsis), Oryza sativa L. (rice), and Gossypium (cotton) are most often used in this research. This work has laid a solid foundation for exploring phytohormone transport between the rootstock and scion in grafted vegetables.

Phytohormones can function either at their site of synthesis or can be transported through the vascular system to tissues relatively far from their source ( $\mathrm{Li}$ and $\mathrm{Li}, 2019$ ). Indole acetic acid (IAA; an auxin), cytokinins (CKs), and jasmonic acid (JA) have been shown to undergo polar transport between rootstocks and scions. For instance, red light sensed by leaves of normal tomato scions activates the synthesis of IAA (Guo et al., 2016), which is transported downward and promotes the normal development of lateral roots of diageotropica (DGT) mutant rootstocks whose organogenesis of lateral roots be abolished (Ivanchenko et al., 2015). In Arabidopsis, CKs and gibberellic acid (GA) can promote scion branch growth (Ko et al., 2014) and internode elongation (Regnault et al., 2015), respectively, through xylem transport (Matsumoto-Kitano et al., 2008; Kiba et al., 2013; Osugi et al., 2017) from root to shoot. Under osmotic stress, cotton roots induce leaves to synthesize a large amount of JA and transport it to the roots, which increases the content of PIP protein in the roots, enhancing their water absorption capacity (Luo et al., 2019). Furthermore, JA biosynthesis is induced by leaf injury, which causes shoot-to-root transport (Gasperini et al., 2015); conversely, carlactone (CL) can be transported upward from the rootstock to the scion, where it is converted into active strigolactone (SL) (Booker et al., 2005). Abscisic acid (ABA) in tomato rootstocks may be transported upward to regulate stomatal closure of scions (Dodd et al., 2009). Furthermore, GA may be produced tomato rootstocks and scions under drought stress (Gaion et al., 2018). However, further investigation using other methods, such as transgenic sequencing and RNA-seq, is needed to determine whether the phenotypic compensation, in mutants whose gene related to phytohormone transport was interfered, caused by grafting is a result of the transport of phytohormones between rootstocks and scions.

Interaction between phytohormones has been widely reported: (i) in biosynthesis - some genes encoding members of the auxin transcription factor ARF family can regulate $\mathrm{CK}$ biosynthesis by binding to the promoter of the adenylate isopentenyltransferase 5(IPT5) (Cheng et al., 2013) or the oxidase gene OsCKX4 (Gao et al., 2014). In addition, several reports have confirmed that other phytohormones [JA, ABA, ethylene (Eth), GA] influence IAA biosynthesis (Cui et al., 2005; Cai et al., 2014; Zhao et al., 2014; Miao et al., 2018. (ii) In function-IAA and GA can regulate the negative gravity response of rice stem by antagonizing the expression of XET (Cui et al., 2005), brassinosteroids (BRs) interact with IAA and phosphatidylinositol signals to regulate vascular morphogenesis in Arabidopsis cotyledons (Lin et al., 2005), in tomato, the ratio of CK/ACC (positively) and ACC/ABA (negatively) is positively and negatively related to leaf growth and photosystem II (PSII) efficiency, respectively (Albacete et al., 2009). (iii) In signal transduction - in Arabidopsis, Eth inhibits taproot elongation through PIN2-mediated auxin-mediated IAA transport (Miao et al., 2018), BRs also regulate the plant gravity response by changing the polar transport of IAA (Li et al., 2005), JA 
controls lateral root formation by regulating auxin biosynthesis and polar transport (Sun et al., 2009), and phloem-mediated CK transport increases IAA biosynthesis (Jones et al., 2010) and polar transport (Bishopp et al., 2011). In rice, under low-phosphorus and low-nitrogen conditions, SL affects root development by altering the transport of IAA from stem to root (Sun et al., 2014).

The molecular mechanism determining the transport mode of phytohormones in grafted seedlings and their regulation after transport is poorly understood. As different combinations of rootstocks and scions have different modes of synthesis and transportation of endogenous hormones (Lacombe and Achard, 2016), further efforts are needed to reveal the metabolic levels and interaction mechanisms of various endogenous hormones in rootstocks and scions after vegetable grafting and to determine how to affect the expression of rootstock traits.

Phytohormone crosstalk is also involved in the regulation of growth in grafted vegetables; and GA and ABA have been shown to regulate growth in grafted tomato (Gaion et al., 2018). These studies suggest that phytohormones (ABA, IAA, and $\mathrm{CK}$ ) may function as long-distance signals in grafted plants.

\section{Mineral Elements}

Mineral elements are generally absorbed by the roots and then transported through the Casparian strip or by membrane transport proteins in the xylem (Thakur et al., 2016). Grafting has been the main method used to investigate ways to improve ion absorption, exclusion, and transport (Rouphael et al., 2008; Savvas et al., 2010b), as well as to confine heavy metal uptake and translocation in vegetables (Lux et al., 2011; Colla et al., 2013). Recently, several groups have reported that plants exposed to salt stress have altered gene expression patterns, metabolic activity, and ion and water transport, which reduces stress damage and restores water balance (Serrano and Gaxiola, 1994; Hasegawa et al., 2000; Si et al., 2010; Wang Q. et al., 2017). For example, it has been shown that Cucurbita rootstocks increase the plant's tolerance to salt stress by excluding $\mathrm{Na}^{+}$from leaf mesophyll cells and sequestering it in the leaf veins, retaining $\mathrm{K}^{+}$in the leaf mesophyll cells, as well as by early ABA-induced stomatal closure (Niu et al., $2018 \mathrm{~b})$. The mechanism of ion $\left(\mathrm{Na}^{+}, \mathrm{K}^{+}, \mathrm{V}^{+}\right.$, and $\left.\mathrm{Cu}^{2+}\right)$ exclusion has also been investigated in watermelon(Citrullus lanatus) rootstocks (Edelstein et al., 2011; Huang et al., 2013a,b; Nawaz et al., 2018) and cucumber(Cucumis sativus) rootstocks (Rouphael et al., 2008). In addition, grafting did not affect the uptake of Cd (cadmium) by the roots of grafted eggplant (Solanum melongena) (Arao et al., 2008) but did affect its transport in the xylem (Savvas et al., 2010a) and xylem loading (Mori et al., 2009).

In summary, the mechanisms by which grafting affects the absorption and transport of mineral elements in vegetables are controlled by the rootstock genotype or by rootstockscion interactions, which can enhance the tolerance of grafted vegetables to high/low mineral element levels. Thus, grafting is one of the direct strategies used to overcome the effects of toxic heavy metals (Edelstein and Ben-Hur, 2018). However, studies of the corresponding genes or proteins are lacking (Shabala, 2003), and further studies are needed to identify the genes and proteins regulating the absorption, exclusion, and transport of toxic ions within grafted vegetables.

\section{PHLOEM-MEDIATED SYSTEMIC TRANSPORT OF MACROMOLECULAR SIGNAL MOLECULES IN ROOTSTOCK-GRAFTED VEGETABLES}

Signaling macromolecules such as RNAs, microRNAs, and proteins move between the rootstocks and scions of grafted horticultural crops during long-distance transport in the reconstructed vascular system. By participating in information exchange between rootstocks and scions, the processes of transcription, gene expression, and protein translation can not only regulate growth but also improve the adaptation of vegetables to the surrounding environment (Lucas et al., 2001; Harada, 2010; Goldschmidt, 2014; Notaguchi, 2015; Warschefsky et al., 2016; Ko and Helariutta, 2017). The translocation of DNA, mRNA, proteins, and siRNAs induced by grafting has become an active research topic (Haroldsen et al., 2012; Wu et al., 2013; Notaguchi and Okamoto, 2015).

\section{"Omics" Analyses of Macromolecule Signal Exchanges Induced by Grafting}

In horticultural plants, different rootstocks can induce significant changes in physiological responses (Ren et al., 2018), photosynthesis (Xu et al., 2018), hormonal responses (Ren et al., 2018), environmental adaptation (Yu et al., 2017; $\mathrm{Xu}$ et al., 2018), and the sugars and aromatic flavors of the plants (Zhao et al., 2018). Extensive mRNA signaling networks have been reported in the model plants A. thaliana (Thieme et al., 2015) and N. benthamiana (Zhang W. et al., 2014) by bioinformatics and "omics" analyses. Using large-scale data analysis technologies (genome-wide transcriptomic and proteomic analyses), researchers can analyze differentially expressed genes (DEGs), differentially expressed miRNAs (DEMs), and differentially accumulated proteins (DAPs) in various grafted plants.

Genome-wide analysis has made it possible to explore the expression patterns of IAA-related transporter genes such as ClLAX, ClPIN, and ClABCB in grafted watermelon in response to abiotic stresses (e.g., salt, drought, and cold), providing insight into the possible roles of the encoded transporters ( $\mathrm{Yu}$ et al., 2017). Transcriptome profiling has been widely applied to analyze the roles of DEGs/DEMs in graft compatibility and abiotic stress resistance using watermelon scions grafted to squash rootstocks (Xu et al., 2016; Ren et al., 2018). Proteomics can be used to analyze the major categories of proteins in different treatments to investigate the mechanisms of graft-enhanced stress tolerance in scions. For example, comparative proteomic analysis was used to show that cucumber scions grafted to Momordica rootstocks could respond to heat stress by differentially accumulating photosynthesis-related proteins (Xu et al., 2018). 
Therefore, "omics" analyses are important techniques that can be used to unravel the differential accumulation and transport of macromolecular signals in grafted vegetables.

\section{mRNAs}

Combined with heterologous grafting methods, RNA sequencing in different species after grafting showed that $>3,000$ endogenous mRNAs migrate between the stock and scion in grafted cucumber and watermelon (Omid et al., 2007; Ham et al., 2009; Zhang W. et al., 2016). In tomato, studies showed that 347 mRNAs move into the stems of the parasite plant dodder (Cuscuta sp.) near the attachment region (LeBlanc et al., 2013; Kim et al., 2014). In addition, some mobile mRNAs have been shown to have biological functions. For example, CmNACP (Ruiz-Medrano et al., 1999), CmGAIP (Haywood et al., 2005), StBEL5 (Banerjee et al., 2006), and PFP-Let6 (Kim et al., 2001) affect plant growth and development (i.e., dwarfing, apical meristem development, tuber growth, and root development, respectively; (Table 1).

Most mRNAs, but not their encoded proteins, are translated and function after transport. For example, tomato systemic protein precursor (prosystemin, $P S$ ) mRNA moves through the graft interface, after which it is unloaded to nucleated cells of the scion. PS mRNA's ability to be translated into PS protein in response to external herbivore and pathogen damage without the PS protein moving - demonstrates one function of mRNA transport (Zhang et al., 2018). Furthermore, longdistance transport of cyclophilin SlCyp1 mRNA is associated with modulation of the root-shoot ratio, which responds to changes in light intensity by regulating root growth (Spiegelman et al., 2015). Finally, antiflorigen PEBP mRNA has been confirmed to be mobile and to inhibit flowering in tomato-tobacco heterografts (Huang et al., 2018).

\section{ncRNAs}

Many non-coding RNAs (ncRNAs), including transfer RNAs (tRNAs), siRNAs, and microRNAs (miRNAs), are found in the phloem sap of pumpkin(Cucurbita moschata) and oilseed rape (Brassica napus L.) (Buhtz et al., 2008; Pant et al., 2008; Zhang et al., 2009; Hu et al., 2016; Zhang W. et al., 2016), and their functions in virus defense, cell signal transmission, and gene expression regulation have been demonstrated.

\section{tRNAs}

Similar to other phloem-specific RNAs, tRNA molecules are selectively transferred into the sieve tubes (Yoo et al., 2004). Pumpkin phloem sap contains many full-length specific tRNA fragments that can interfere with ribosomal activity and effectively block translation. The tRNA fragments delivered to the phloem are potential long-distance signals; for example, cytokinin-containing tRNAs that can breakdown into free cytokinins are a source of CK (cytokinins) (Mok and Mok, 2001; Table 2). Non-coding RNAs (longer than si/miRNAs) that range from 30 to 90 nucleotides are also found in pumpkin phloem exudates and may inhibit protein translation (Zhang et al., 2009).

\section{si/miRNAs}

Zhang W. et al. (2014) reported that si/miRNAs function in systemic acquired resistance and mineral element uptake after they are transported through the phloem in both model plants and vegetables. Buhtz et al. (2010) showed that the mobility of miRNAs produced in rootstocks through the graft union helps the scion (miRNA processing hen1-1 mutant, in this case) respond to nutrient deprivation. Nutrient starvation experiments showed that the levels of miR395, miR398, and miR399 in the phloem sap of B. napus were significantly increased in response to sulfate, copper, and phosphate starvation, respectively (Table 2). In particular, miR399 levels are markedly increased in lowphosphate medium, which is consistent with earlier studies in A. thaliana (Fujii et al., 2005; Bari et al., 2006; Chiou et al., 2006). CsmiR399a/e is upregulated to induce the tissue-specific transport of mRNAs under inorganic phosphate stress after grafting in cucumbers (Pant et al., 2008; Nawaz et al., 2016; Zhang Z. et al., 2016).

Visual markers can be used to track the distribution of siRNAs in the plant vascular system. Using asexual and sexual progeny of chimeras that consist of red cabbage (B. oleracea var. capitata) and tuber mustard (Brassica juncea var. tumida) after grafting (Li et al., 2013) showed that siRNAs are transported from the red cabbage to the tuber mustard, and that the transport of siRNAs created a heritable variation. Research on si/miRNA transportation provides a theoretical basis for using transgenesis to create an RNA interference vector to produce plants with reduced expression of related genes.

\section{Proteins}

Numerous studies have shown that phloem sap contain proteins that can move not only between adjacent cells and distant cells, but also between the rootstock and scion in grafted plants. Functional mobile proteins that move between the rootstock and scion include the transport proteins $\mathrm{CmPP} 1$ and CmPP2 (Tiedemann and Carstens-Behrens, 1994; Golecki et al., 1999), the florigen CmFT (Lin et al., 2007), and CmSTMwhich determines cell fate in the meristem (Groot et al., 2005; Table 1).

At least nine additional phloem transport proteins, such as CmPP16 and CmHSP70, or their precursors, form a ribonucleoprotein (RNP) complex that is also present in the phloem of both the rootstock and the scion, indicating that the proteins are exchanged through the reconstructed vascular system (Golecki et al., 1998; Xoconostle-Cázares et al., 1999). A model in which RNP complexes based on CmRBP50 function in the translocation stream has been proposed for pumpkin phloem (Ham et al., 2009) and B. napus phloem sap (Ostendorp et al., 2017). Similar to CmRBP50, CmWRKYP, CmPP2, Cmlec17, and CmPP16 are phloem RNAbinding proteins that can also help RNA transport via phloem (Ham et al., 2009).

Taken together, analyses of phloem sap collected from cucumber, watermelon, pumpkin, and B. napus have revealed significant differences in the metabolism and proteome characteristics of shoot-root junction regions and those of the sieve tube system (STS) (Cho et al., 2015; Hu et al., 2016; Zhang W. et al., 2016; Ham and Lucas, 2017; Wang J. et al., 2017; Kehr and Kragler, 2018). These observations suggest that the STS is a distinct and extremely complex metabolic space in the plant vascular system that facilitates stock-scion communication. 
TABLE 1 | Overview of mobile mRNAs and proteins that have been identified in grafted vegetables.

\begin{tabular}{|c|c|c|c|}
\hline Class & Name & Detection method & References \\
\hline \multirow[t]{8}{*}{ mRNA } & 347 tomato mRNAs & cDNA libraries & Kim et al., 2014 \\
\hline & 3546 Cucurbita maxima mRNAs & RNA-Seq SNPs & Zhang Z. et al., 2016 \\
\hline & CmPP16 & RT-PCR & Xoconostle-Cázares et al., 1999 \\
\hline & CMNACP & RT-PCR & Ruiz-Medrano et al., 1999 \\
\hline & SIPFP-LeT6 & in situ RT-PCR & Kim et al., 2001 \\
\hline & CmGAIP & RT-PCR & Haywood et al., 2005 \\
\hline & StBEL5 & RT-PCR & Banerjee et al., 2006 \\
\hline & SIPS & RT-PCR & Zhang et al., 2018 \\
\hline \multirow[t]{5}{*}{ Protein } & CmPP1/PP2 & Western Blot & Tiedemann and Carstens-Behrens, 1994 \\
\hline & CmPP16 & Western Blot & Xoconostle-Cázares et al., 1999 \\
\hline & $\mathrm{CmFT}$ & Mass Spectrum & Lin et al., 2007 \\
\hline & CmRBP50 & Gel mobility-shift assays & Ham et al., 2009 \\
\hline & SICyp1 & Western Blot & Spiegelman et al., 2015 \\
\hline
\end{tabular}

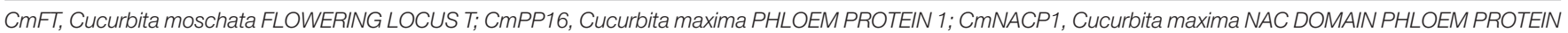

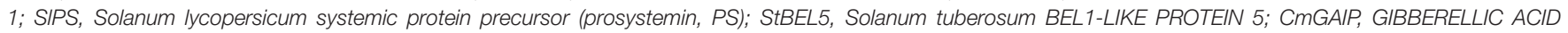

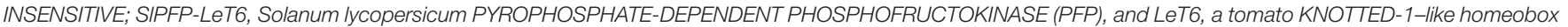
(KNOX) gene, PFP-LeT6 fusion mRNA; CmRBP50, RNA Binding Protein 50; SICyp1, Solanum lycopersicum Cyclophilin 1.

TABLE 2 | Overview of mobile non-coding RNAs that have been identified in grafted vegetables.

\begin{tabular}{|c|c|c|c|c|}
\hline Crop & non-coding RNA & Transport direction & Function description & References \\
\hline Solanum tuberosum L. & $\operatorname{miR} 172$ & shoot to root & Promote flowering, accelerates tuberization & Martin et al., 2009 \\
\hline Brassica napus L. & $\operatorname{miR395}$ & shoot to root & Sulfate starvation & Jones-Rhoades and Bartel, 2004 \\
\hline Brassica napus L. & miR398 & shoot to root & Copper starvation & Sunkar et al., 2006 \\
\hline Brassica napus L. & miR399 & shoot to root & Phosphate starvation & Pant et al., 2008 \\
\hline Cucurbita maxima & tRNA & shoot to root & The source of cytokinins & Mok and Mok, 2001 \\
\hline
\end{tabular}

\section{Studies on the Mechanism of RNA and Protein Signaling Between the Rootstock and Scion in Grafted Vegetables}

The mechanism of mRNA signaling in vegetable plants is not particularly well understood. It is uncertain whether the mechanism of mRNA transport is sequence-specific or nonsequence-specific. It has been reported that mRNA transport in A. thaliana may be (i) directional and tissue specific (Wang J. et al., 2017; Kehr and Kragler, 2018); (ii) independent of transcript abundance and stability (Calderwood et al., 2016); and (iii) facilitated by a specific tertiary structural sequence (Zhong et al., 2007), homodomain region (Kim et al., 2001), 3'-UTR (Haywood et al., 2005; Huang and Yu, 2009), poly-CU (Ham et al., 2009), TLS (tRNA-related sequence) (Zhang W. et al., 2016), and 5-methylcytosine modifications (Yang et al., 2019) that recognize cytoplasmic ribosomes and chaperones, altering RNA self-conformation and the plasmodesma exclusion limit (SEL), as well as by selective loading and unloading in the CC-SE (companion cell-sieve element) (Figure 1).

Transport of small RNA molecules via the phloem is mediated by the RNA-binding protein CmPSRP1 (Yoo et al., 2004). CmPSRP1 isolated from pumpkin phloem selectively binds to single-stranded siRNAs and mediates their intercellular trafficking through plasmodesmata, which is consistent with the function of CmPSRP1 in transporting siRNA through CC-SE plasmodesmata. These observations are related to the mechanism of siRNA-related gene silencing (Ham et al., 2009, 2014; Hu et al., 2016).

The mechanism of RNA and protein signaling between rootstock and scion in horticultural plants has been studied only in cucurbits, tomato, and Brassica species. Large-scale "omics" data analyses suggest that mRNA transport in grafted vegetables is directional and specific, and that the transcripts function after transport. Further studies that use gene-editing technology and focus on species-specific traits are needed.

\section{DISCUSSION}

Vegetables are exposed to various biotic and abiotic stresses that threaten production in open-field and greenhouse cultivation, in part because of continuous cropping (Cohen et al., 2000, 2005, 2007; Yu et al., 2017). Grafting has long been used to regulate plant growth and improve biotic and abiotic stress tolerance in the production of horticultural plants ( $\mathrm{Xu}$ et al., 2018). Grafting has been studied for its striking effects on fruit quality (Bertucci et al., 2018; Zhao et al., 2018; Garcia-Lozano et al., 2020), physiological responses (Ren et al., 2018), and photosynthesis (Xu et al., 2018). Furthermore, heterografting is a powerful tool for identifying horizontal DNA movement (Yu et al., 2017) and the long-distance transport of mRNAs (Banerjee et al., 2006; Ham et al., 2009; Xu et al., 2016; Huang et al., 2018), ncRNAs (Mok and Mok, 2001; Yoo et al., 2004; 


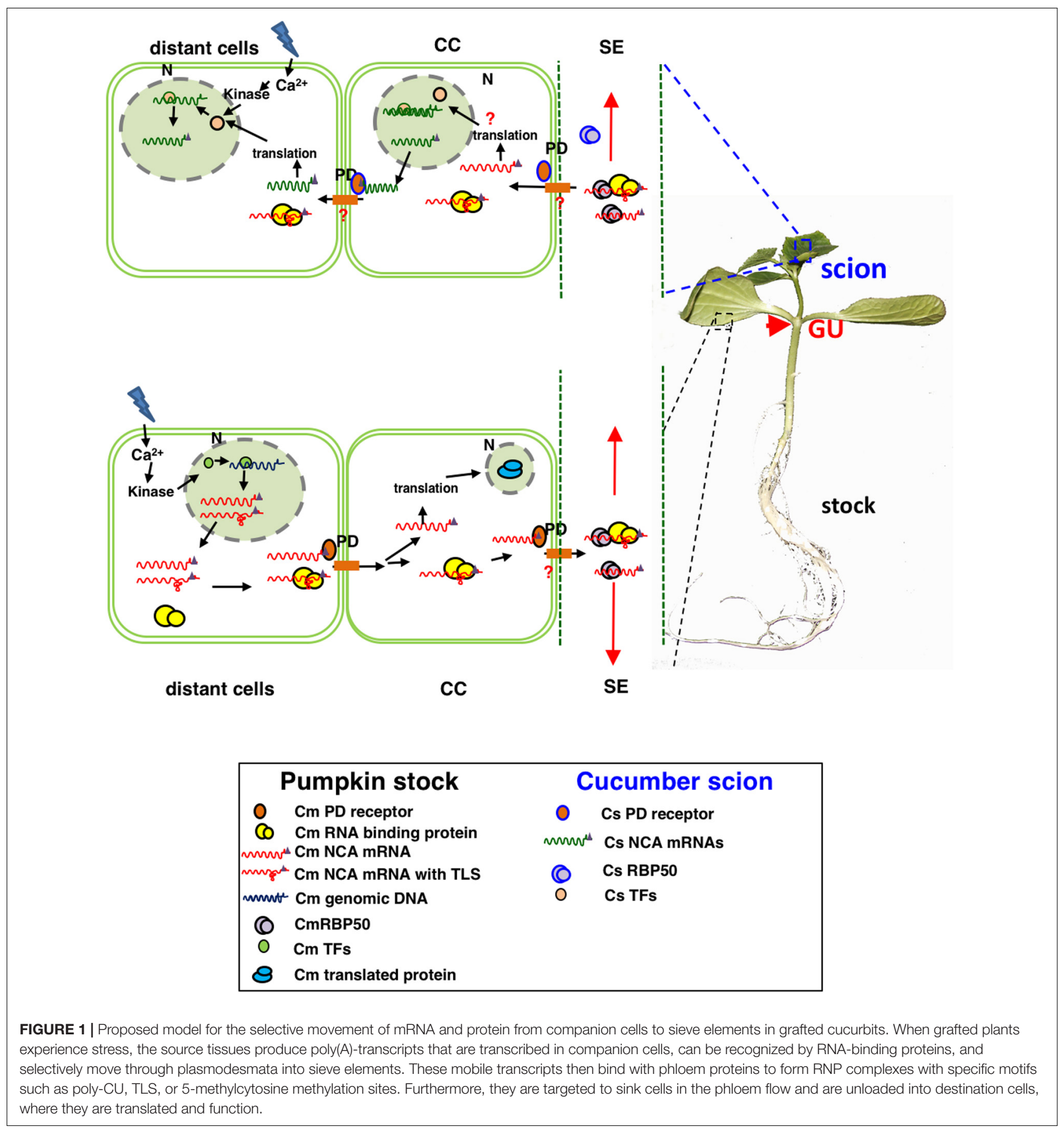

Zhang et al., 2009; Ren et al., 2018), and proteins (Lin et al., 2007; Xu et al., 2018). Compared with those done in fruit trees, there are fewer studies on the physiological and molecular aspects of rootstock-scion interaction in vegetables. Currently, grafting is principally used in the Cucurbitaceae (watermelon, melon, cucumber) and Solanaceae (tomato, pepper, eggplant) families and has become a more commonly used and more efficient technique for studies aimed at elucidating the underlying mechanism(s) of the rootstock-scion interaction in vegetables than grafting for such studies in fruit trees. First, vegetables are herbaceous plants with short growth cycles $(<2$ years per growth cycle), so it is more convenient to investigate phenotypic changes during the growth and development of vegetables than during those of fruit trees. Second, owing to the high heterozygosity of germplasm resources in fruit trees, it is easier to obtain homozygous vegetable plants whose gene sequence is 


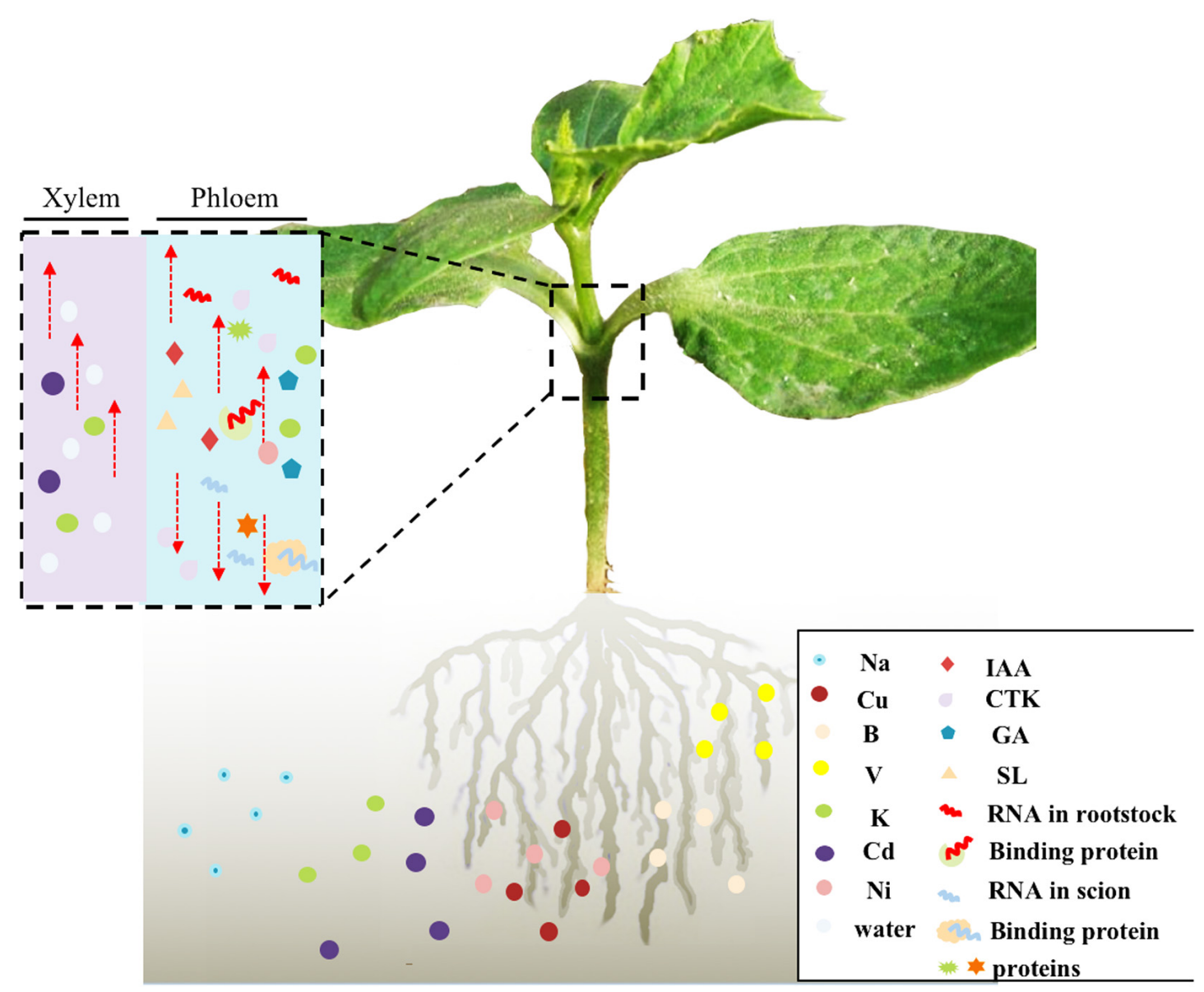

FIGURE 2 | Proposed model of systemic long-distance signal transport in distant tissues of grafted vegetables. Grafting material: cucumber/pumpkin cotyledon-insertion grafts. Directionality: mineral elements and water acquired by the rootstock can be transported to the scion through the xylem; and plant hormones, some microRNAs, and proteins can be transported through the phloem rootstock-scion communication pathway in grafted vegetables. In addition, some binding proteins can transport RNAs. Selectivity: rootstocks of grafted vegetables will selectively absorb or reject mineral elements in the rhizosphere so as to achieve tolerance of grafted vegetables to high/low mineral element levels.

stable, which are advantageous for studies on rootstock-scion signaling exchanges. Third, gene modification/editing technology and ethyl methanesulfonate (EMS) mutation screen technology have been established in vegetables, especially in Cucurbitaceae (watermelon, cucumber) and Solanaceae (tomato), which offers more opportunity to study rootstock-scion signaling exchange and interaction by grafting mutants to transgenic plants. In a word, there is an urgent need for studies on rootstock breeding and the rootstock-scion interaction in grafted vegetables.

Unraveling the mechanisms that control vascular-delivered signaling molecules in grafted vegetables would enable the selection of suitable rootstock resources and also help to explain how grafting improves quality in vegetables. Several studies have focused on the changes in and transport of phytohormones (Noorden et al., 2006; Hirose et al., 2008), minerals (Huang et al., 2013b; Niu et al., 2018a), mRNAs (Omid et al., 2007; Ham et al., 2009; Zhang W. et al., 2016), ncRNAs (Buhtz et al., 2008; Pant et al., 2008), and proteins (Kehr and Kragler, 2018; Xu et al., 2018) that are induced by grafting. Some phytohormones (Ko et al., 2014; Ivanchenko et al., 2015; Regnault et al., 2015; Guo et al., 2016), mRNAs (Haywood et al., 2005; Banerjee et al., 2006), ncRNAs (Li et al., 2013), and proteins (Groot et al., 2005; Ham et al., 2009) that can be transported via the vascular system have been proven to have definite functions (Figure 2). Researchers have speculated about the mechanisms of RNA and protein phloem transport/co-transport, in regard to tissue specificity (Wang J. et al., 2017; Kehr and Kragler, 2018), whether specific structural sequences are required (Kim et al., 2001; Haywood et al., 2005; Huang and Yu, 2009; Ham et al., 2009; Zhang W. et al., 2016; Yang et al., 2019), and the role of RNA-binding proteins (Yoo et al., 2004; Ham et al., 2009; Ostendorp et al., 2017). Generally, research on grafted vegetables has mainly focused on stress resistance (Rouphael et al., 2008; Yu et al., 2017), graft compatibility (Ren et al., 2018), hormonal responses (Albacete et al., 2009; Gaion et al., 2018), and long-distance transport signals in vascular systems (Lin et al., 2007; Li et al., 2013; Zhang et al., 2018; Huang et al., 2018). Nevertheless, "omics" analyses 
are direct and rapid methods of detecting and identifying mobile and differentially expressed substances (Yu et al., 2017), such as DEGs (Xu et al., 2016), DEMs (Ren et al., 2018), and DAPs (Xu et al., 2018) in grafted vegetables; however, results obtained from "omics" datasets need to be verified by combining more biological experiments, such as fluorescence quantitative analysis of gene expression pattern.

\section{CONCLUSION}

Despite the current state of research, the mechanisms that control the changes in and transport of specific molecules in vegetable grafts remain poorly understood. In particular, the basic questions (what, when, where, and how) concerning the transport of signal substances between rootstock and scion remain to be addressed and merit further study. Moreover, a scientific explanation for the long-distance trafficking of RNAs and proteins in rootstock grafts remains to be determined. This

\section{REFERENCES}

Albacete, A., Martinez-Andujar, C., Ghanem, M. E., Acosta, M., Sanchez-Bravo, J., Asins, M. J., et al. (2009). Rootstock-mediated changes in xylem ionic and hormonal status are correlated with delayed leaf senescence, and increased leaf area and crop productivity in salinized tomato. Plant Cell Environ. 32, 928-938. doi: 10.1111/j.1365-3040.2009.01973.x

Arao, T., Takeda, H., and Nishihara, E. (2008). Reduction of cadmium translocation from roots to shoots in eggplant (Solanum melongena) by grafting onto Solanum torvum rootstocks. Soil Sci Plant Nutr. 54, 555-559. doi: 10.1111/j. 1747-0765.2008.00269.x

Banerjee, A. K., Chatterjee, M., Yu, Y., Suh, S. G., Miller, W. A., and Hannapel, D. J. (2006). Dynamics of a mobile RNA of potato involved in a long-distance signaling pathway. Plant Cell 18, 3443-3457. doi: 10.1105/tpc.106.042473

Bari, R., Pant, B. D., Stitt, M., and Scheible, W. R. (2006). PHO2, microRNA399, and PHR1 define a phosphate-signaling pathway in plants. Plant Physiol. 141, 988-999. doi: 10.1104/pp.106.079707

Bertucci, M. B., Jennings, K. M., Monks, D. W., Schultheis, J. R., Perkins-Veazie, P., Louws, F. J., et al. (2018). Early season growth, yield, and fruit quality of standard and mini watermelon grafted onto several commercially available cucurbit rootstocks. Hort Technol. 28, 459-469. doi: 10.21273/horttech0405118 doi: 10.21273/horttech04051-18

Bishopp, A., Lehesranta, S., Vaten, A., Help, H., El-Showk, S., Scheres, B., et al. (2011). Phloem-transported cytokinin regulates polar auxin transport and maintains vascular pattern in the root meristem. Curr. Biol. 21, 917-926. doi: 10.1016/j.cub.2011.04.049

Booker, J., Sieberer, T., Wright, W., Williamson, L., Willett, B., Stirnberg, P., et al. (2005). MAX1 encodes a cytochrome P450 family member that acts downstream of $M A X 3 / 4$ to produce a carotenoid-derived branch-inhibiting hormone. Dev. Cell 8, 443-449. doi: 10.1016/j.devcel.2005.01.009 doi: 10.1016/ j.devcel.2005.01.009

Buhtz, A., Pieritz, J., Springer, F., and Kehr, J. (2010). Phloem small RNAs, nutrient stress responses, and systemic mobility. BMC Plant Biol. 10, 64-70.

Buhtz, A., Springer, F., Chappell, L., Baulcombe, D. C., and Kehr, J. (2008). Identification and characterization of small RNAs from the phloem of Brassica napus. Plant J. 53, 739-749. doi: 10.1111/j.1365-313x.2007.03368.x

Cai, X., Xu, P., Zhao, P., Liu, R., Yu, L., Xiang, C., et al. (2014). Arabidopsis ERF109 mediates cross-talk between jasmonic acid and auxin biosynthesis during lateral root formation. Nat. Commun. 5:5833.

Calderwood, A., Kopriva, S., and Morris, R. J. (2016). Transcript abundance explains mRNA mobility data in Arabidopsis thaliana. Plant Cell 28, 610-615. doi: $10.1105 /$ tpc. 15.00956

Cheng, Z., Wang, L., Sun, W., Zhang, Y., Zhou, C., Su, Y., et al. (2013). Pattern of auxin and cytokinin responses for shoot meristem induction results from the explanation will also provide a theoretical basis for rootstock breeding and selection to meet specific demands for efficient vegetable production.

\section{AUTHOR CONTRIBUTIONS}

XHL and WZ wrote the final manuscript. WL wrote mRNA and protein part. TW wrote non-coding RNA part. JZ wrote nutrient transport part. XJL wrote hormone transport part.

\section{FUNDING}

This work was supported by grants from the National Key Research and Development Program of China (2018YFD1000800) and the National Natural Science Foundation of China (31872158).

regulation of cytokinin biosynthesis by Auxin response Factor3. Plant Physiol. 161, 240-251. doi: 10.1104/pp.112.203166

Chiou, T. J., Aung, K., Lin, S., Wu, C., Chiang, S., and Su, C. (2006). Regulation of phosphate homeostasis by microRNA in Arabidopsis. Plant Cell 18, 412-421. doi: 10.1105/tpc.105.038943

Cho, S. K., Sharma, P., Butler, N. M., Kang, I. H., Shah, S., Rao, A. G., et al. (2015). Polypyrimidine tract-binding proteins of potato mediate tuberization through an interaction with StBEL5 RNA. J. Exp. Bot. 66, 6835-6847. doi: 10.1093/jxb/erv389

Cohen, R., Burger, Y., Horev, C., Porat, A., and Edelstein, M. (2005). Performance of Galia type melons grafted onto Cucurbita rootstock in Monosporascus cannonballus-infested and non-infested soils. Ann. Appl. Biol. 146, 381-387. doi: 10.1111/j.1744-7348.2005.040010.x

Cohen, R., Burger, Y., Horev, C., Porat, A., and Edelstein, M. (2007). Introducing grafted cucurbits to modern agriculture: the Israeli experience. Plant Dis. 91, 916-923. doi: 10.1094/pdis-91-8-0916

Cohen, R., Pivonia, S., Burger, Y., Edelstein, M., Gamliel, A., and Katan, J. (2000). Toward integrated management of Monosporascus wilt of melons in Israel. Plant Dis. 84, 496-505. doi: 10.1094/pdis.2000.84.5.496

Colla, G., Kumar, P., Cardarelli, M., and Rouphael, Y. (2013). "Grafting: an effective tool for abiotic stress alleviation in vegetables," in Horticulture for Food and Environment Security, eds K. L. Chanda, A. K. Singh, S. K. Singh, and W. S. Dhillon (New Delhi: Westville Publishing House), 15-28.

Cui, D., Neill, S., Tang, Z., and Cai, W. (2005). Gibberellin-regulated XET is differentially induced by auxin in rice leaf sheath bases during gravitropic bending. J. Exp. Bot. 56, 1327-1334. doi: 10.1093/jxb/eri133

Davis, A. R., Perkins-Veazie, P., Hassell, R., Levi, A., King, S. R., and Zhang, X. (2008). Grafting effects on vegetable quality. HortScience 43, 1670-1672. doi: 10.21273/hortsci.43.6.1670

Dodd, I. C., Theobald, J. C., Richer, S. K., and Davies, W. J. (2009). Partial phenotypic reversion of ABA-deficient flacca tomato (Solanum lycopersicum) scions by a wild- type rootstock: normalizing shoot ethylene relations promotes leaf area but does not diminish whole plant transpiration rate. J. Exp. Bot. 60, 4029-4039. doi: 10.1093/jxb/erp236

Edelstein, M., and Ben-Hur, M. (2018). Heavy metals and metalloids: sources, risks and strategies to reduce their accumulation in horticultural crops. Sci, Hortic.. 234, 431-444. doi: 10.1016/j.scienta.2017.12.039

Edelstein, M., Plaut, Z., and Ben-Hur, M. (2011). Sodium and chloride exclusion and retention by non-grafted and grafted melon and Cucurbita plants. J. Exp. Bot. 62, 177-184. doi: 10.1093/jxb/erq255

Fredes, A., Rosello, S., Beltran, J., Cebolla-Cornejo, J., Perez-de-Castro, A., Gisbert, C., et al. (2017). Fruit quality assessment of watermelons grafted onto citron melon rootstock. J. Sci. Food Agricul. 97, 1646-1655. doi: 10.1002/jsfa. 7915 
Fujii, H., Chiou, T. J., Lin, S., Aung, K., and Zhu, J. K. (2005). A miRNA involved in phosphate-starvation response in Arabidopsis. Curr. Biol. 15, 2038-2043. doi: 10.1016/j.cub.2005.10.016

Gaion, L. A., Monteiro, C. C., Cruz, F. J. R., Rossatto, D. R., Lopez-Diaz, I., Carrera, E., et al. (2018). Constitutive gibberellin response in grafted tomato modulates root-to-shoot signaling under drought stress. J. Plant Physiol. 221, 11-21. doi: 10.1016/j.jplph.2017.12.003

Gao, S., Fang, J., Xu, F., Wang, W., Sun, X., Chu, J., et al. (2014). CYTOKININ OXIDASE/DEHYDROGENASE4 integrates cytokinin and auxin signaling to control rice crown root formation. Plant Physiol. 165, 1035-1046. doi: 10.1104/ pp.114.238584

Garcia-Lozano, M., Dutta, S. K., Natarajan, P., Tomason, Y. R., Lopez, C., Katam, R., et al. (2020). Transcriptome changes in reciprocal grafts involving watermelon and bottle gourd reveal molecular mechanisms involved in increase of the fruit size, rind toughness and soluble solids. Plant Mol. Biol. 102, 213-223. doi: 10.1007/s11103-019-00942-7

Gasperini, D., Chauvin, A., Acosta, I. F., Kurenda, A., Stolz, S., Chetelat, A., et al. (2015). Axial and radial oxylipin transport. Plant Physiol. 169, 2244-2254.

Goldschmidt, E. E. (2014). Plant grafting: new mechanisms, evolutionary implications. Front. Plant Sci. 5:727. doi: 10.3389/fpls.2014.00727

Golecki, B., Schulz, A., Carstens-Behrens, U., and Kollmann, R. (1998). Evidence for graft transmission of structural phloem proteins or their precursors in heterografts of Cucurbitaceae. Planta 206, 630-640. doi: 10.1007/ s004250050441

Golecki, B., Schulz, A., and Thompson, G. A. (1999). Translocation of structural P proteins in the phloem. Plant Cell 11, 127-140. doi: 10.1105/tpc.11.1.127

Groot, E. P., Sinha, N., and Gleissberg, S. (2005). Expression patterns of STMlike KNOX and Histone $\mathrm{H} 4$ genes in shoot development of the dissectedleaved basal eudicot plants Chelidonium majus and Eschscholzia californica (Papaveraceae). Plant Mol. Biol. 58, 317-331. doi: 10.1007/s11103-005-4548-1

Guo, Z., Wang, F., Xiang, X., Ahammed, G. J., Wang, M., Onac, M., et al. (2016) Systemic induction of photosynthesis via illumination of the shoot apex is mediated sequentially by phytochrome $B$, auxin and hydrogen peroxide in tomato. Plant Physiol. 172, 1259-1272. doi: 10.1104/pp.16.01202

Ham, B. K., Brandom, J. L., Xoconostle-Cázares, B., Ringgold, V., Lough, T. J., and Lucas, W. J. (2009). A polypyrimidine tract binding protein, pumpkin RBP50, forms the basis of a phloem-mobile ribonucleoprotein complex. Plant Cell 21, 197-215. doi: 10.1105/tpc.108.061317

Ham, B. K., Li, G., Jia, W. T., Leary, J. A., and Lucas, W. J. (2014). Systemic delivery of siRNA in pumpkin by a plant phloem small RNA-binding protein PHLOEM SMALL RNA-BINDING PROTEIN 1-ribonucleoprotein complex. Plant J. 4, 683-694. doi: 10.1111/tpj.12662

Ham, B. K., and Lucas, W. J. (2017). Phloem-mobile RNAs as systemic signaling agents. Annu. Rev. Plant Biol. 68, 173-195. doi: 10.1146/annurev-arplant042916-041139

Harada, T. (2010). Grafting and RNA transport via phloem tissue in horticultural plants. Sci. Hortic. 125, 545-550. doi: 10.1016/j.scienta.2010.05.013

Haroldsen, V. M., Chi-Ham, C. L., and Bennett, A. B. (2012). Transgene mobilization and regulatory uncertainty for non-GE fruit products of transgenic rootstocks. J. Biotechnol. 161, 349-353. doi: 10.1016/j.jbiotec.2012. 06.017

Hasegawa, M., Bressan, R., and Pardo, J. M. (2000). The dawn of plant salt tolerance genetics. Trends Plant Sci. 5, 317-319. doi: 10.1016/s1360-1385(00)01692-7

Haywood, V., Yu, T. S., Huang, N. C., and Lucas, W. J. (2005). Phloem longdistance trafficking of GIBBERELLIC acid-insensitive RNA regulates leaf development. Plant J. 42, 49-68. doi: 10.1111/j.1365-313x.2005.02351.x

Hirose, N., Takei, K., Kuroha, T., Kamada-Nobusada, T., Hayashi, H., and Sakakibara, H. (2008). Regulation of cytokinin biosynthesis, compartmentalization and translocation. J. Exp. Bot. 59, 75-83. doi: $10.1093 /$ jxb/erm 157

Hu, C., Ham, B. K., El-Shabrawi, H. M., Alexander, D., Zhang, D., Ryals, J., et al. (2016). Proteomics and metabolomics analyses reveal the cucurbit sieve tube system as a complex metabolic space. Plant J. 87, 442-454. doi: 10.1111/tpj. 13209

Huang, N., Luo, K., and Yu, T. (2018). Mobility of antiflorigen and PEBP mRNAa in tomato-tobacco heterografts. Plant Physiol. 178, 783-794. doi: 10.1104/pp. 18.00725
Huang, N., and Yu, T. (2009). The sequences of Arabidopsis GA INSENSITIVE RNA constitute the motifs that are necessary and sufficient for RNA longdistance trafficking. Plant J. 59, 921-929. doi: 10.1111/j.1365-313x.2009.03918.x

Huang, Y., Bie, Z., Liu, P., Niu, M. L., Zhen, A., Liu, Z., et al. (2013a). Reciprocal grafting between cucumber and pumpkin demonstrates the roles of the rootstock in the determination of cucumber salt tolerance and sodium accumulation. Sci. Hortic. 149, 47-54. doi: 10.1016/j.scienta.2012.04.018

Huang, Y., Li, J., Hua, B., Liu, Z., Fan, M. L., and Bie, Z. L. (2013b). Grafting onto different rootstocks as a means to improve watermelon tolerance to low potassium stress. Sci. Hortic. 149, 80-85. doi: 10.1016/j.scienta.2012.02.009

Ioannou, N. (2001). Integrating soil solarization with grafting on resistant rootstocks for management of soil-borne pathogens of eggplant. Journal Hortic. Sci. Biotechnol. 76, 396-401. doi: 10.1080/14620316.2001.11511383

Ivanchenko, M. G., Zhu, J., Wang, B., Medvecka, E., Du, Y., Azzarello, E., et al. (2015). The cyclophilin A DIAGEOTROPICA gene affects auxin transport in both root and shoot to control lateral root formation. Development 142, 712-721. doi: 10.1242/dev.113225

Jones, B., Gunnerås, S. A., Petersson, S. V., Tarkowski, P., Graham, N., May, S., et al. (2010). Cytokinin regulation of auxin synthesis in Arabidopsis involves a homeostatic feedback loop regulated via auxin and cytokinin signal transduction. Plant Cell 22, 2956-2969. doi: 10.1105/tpc.110.074856

Jones-Rhoades, M. W., and Bartel, D. P. (2004). Computational identification of plant microRNAs and their targets, including a stress induced miRNA. Mol. Cell. 14, 787-799. doi: 10.1016/j.molcel.2004.05.027

Kakizaki, T., Kitashiba, H., Zou, Z., Li, F., Fukino, N., Ohara, T., et al. (2017). A 2-Oxoglutarate-dependent dioxygenase mediates the biosynthesis of glucoraphasatin in radish. Plant Physiol. 173, 1583-1593. doi: 10.1104/pp.16. 01814

Kehr, J., and Kragler, F. (2018). Long distance RNA movement. New Phytol. 218, 29-40. doi: 10.1111/nph.15025

Kiba, T., Takei, K., Kojima, M., and Sakakibara, H. (2013). Side-chain modification of cytokinins controls shoot growth in Arabidopsis. Dev. Cell 27, 452-461. doi: 10.1016/j.devcel.2013.10.004

Kim, G., LeBlanc, M. L., Wafula, E. K., Depamphilis, C. W., and Westwood, J. H. (2014). Genomic-scale exchange of mRNA between a parasitic plant and its hosts. Science 10:1126.

Kim, M., Canio, W., Kessler, S., and Sinha, N. (2001). Developmental changes due to long-distance movement of a homeobox fusion transcript in tomato. Science 5528, 287-289. doi: 10.1126/science. 1059805

Ko, D., and Helariutta, Y. (2017). Shoot-root communication in flowering plants. Curr. Biol. 27, 973-978.

Ko, D., Kang, J., Kiba, T., Park, J., Kojima, M., and Do, J. (2014). Arabidopsis ABCG14 is essential for the root-to-shoot translocation of cytokinin. Proc. Natl. Acad. Sci. U.S.A. 111, 7150-7155. doi: 10.1073/pnas.1321519111

Lacombe, B., and Achard, P. (2016). Long-distance transport of phytohormones through the plant vascular system. Curr. Opin. Plant Biol. 34, 1-8. doi: 10.1016/ j.pbi.2016.06.007

LeBlanc, M., Kim, G., Patel, B., Stromberg, V., and Westwood, J. (2013). Quantification of tomato and Arabidopsis mobile RNAs trafficking into the parasitic plant Cuscuta pentagona. New Phytol. 200, 1225-1233. doi: 10.1111/ nph.12439

Lee, J., Kubota, C., Tsaoc, S. J., Bie, Z., Echevarria, P. H., Morra, L., et al. (2010). Current status of vegetable grafting: diffusion, grafting techniques, automation. Sci. Hortic. 127, 93-105. doi: 10.1016/j.scienta.2010.08.003

Lee, T., Sarwinski, S., Ishine, T., Lai, C., and Chen, F. (1996). Inhibition of cerebral neurogenic vasodilation by L-glutamine and nitric oxide synthase inhibitors and its reversal by L-citrulline. J. Pharmacol. Exp. Ther. 276, 353-358.

$\mathrm{Li}$, J., and Li, C. (2019). Seventy-year major research progress in plant hormones by Chinese scholars (in Chinese). Sci. Sin. Vitae 49, 1227-1281.

Li, J., Wang, Y., Zhang, L., Liu, B., Cao, L., Qi, Z., et al. (2013). Heritable variation and small RNAs in the progeny of chimeras of Brassica juncae and Brassica oleraceae. J. Exp. Bot. 64, 4851-4862. doi: 10.1093/jxb/ert266

Li, L., Xu, J., Xu, Z., and Xue, H. (2005). Brassinosteroids stimulate plant tropisms through modulation of polar auxin transport in Brassica and Arabidopsis. Plant Cell 17, 2738-2753. doi: 10.1105/tpc.105.034397

Lin, M., Belanger, H., Lee, Y., Varkonyi-Gasic, E., Taoka, K. I., Miura, E., et al. (2007). Flowering Locus T Protein may act as the long-distance florigenic signal in the Cucurbits. Plant Cell 19, 1488-1506. doi: 10.1105/tpc.107.051920 
Lin, W., Wang, Y., Mueller-Roeber, B., Brearley, C. A., Xu, Z., and Xue, H. (2005). At5PTase 13 modulates cotyledon vein development through regulating auxin homeostasis. Plant Physiol. 139, 1677-1691. doi: 10.1104/pp.105.067140

Lucas, W. J., Yoo, B. C., and Kragler, F. (2001). RNA as a long-distance information macromolecule in plants. Nat. Rev. Mol. Cell Biol. 2, 849-857. doi: 10.1038/35099096

Luo, Z., Kong, X., Zhang, Y., Li, W., Zhang, D., Dai, J., et al. (2019). Leaf-derived jasmonate mediates water uptake from hydrated cotton roots under partial root-zone irrigation. Plant Physiol. 180, 1660-1676. doi: 10.1104/pp.19.00315

Lux, A., Martinka, M., Vaculik, M., and White, P. J. (2011). Root response to cadmium in the rhizosphere: a review. J. Exp. Bot. 62, 21-37. doi: 10.1093/jxb/erq281

Martin, A., Adam, H., Diaz-Mendoza, M., Zurczak, M., Gonzalez-Schain, N. D., and Suarez-Lopez, P. (2009). Graft-transmissible induction of potato tuberization by the microRNA miR172. Development 136, 2873-2881.

Matsumoto-Kitano, M., Kusumoto, T., Tarkowski, P., Kinoshita-Tsujimura, K., Vaclavikova, K., Miyawaki, K., et al. (2008). Cytokinins are central regulators of cambial activity. Proc. Natl. Acad. Sci. U.S.A. 105, 20027-20031.

Miao, Z., Zhao, P., Mao, J., Yu, L., Yuan, Y., Tang, H., et al. (2018). HOMEOBOX PROTEIN52 mediates the crosstalk between ethylene and auxin signaling during primary root elongation by modulating auxin transport-related gene expression. Plant Cell 30, 2761-2778. doi: 10.1105/tpc.18.00584

Mok, D. W. S., and Mok, M. C. (2001). Cytokinin metabolism and action. Ann. Re. Plant Physiol. Plant Mol. Biol. 52, 89-118.

Mori, S., Uraguchi, S., Ishikawa, S., and Arao, T. (2009). Xylem loading process is a critical factor in determining $\mathrm{Cd}$ accumulation in the shoots of Solanum melongena and Solanum torvum. Environ. Environ. Exp. Bot. 67, 127-132. doi: 10.1016/j.envexpbot.2009.05.006

Nawaz, M. A., Chen, C., Shireen, F., Zheng, Z., Jiao, Y., Sohail, H., et al. (2018). Improving vanadium stress tolerance of watermelon by grafting onto bottle gourd and pumpkin rootstock. Plant Growth Regul. 85, 41-56. doi: 10.1007/ s10725-018-0372-x

Nawaz, M. A., Imtiaz, M., Kong, Q. S., Cheng, F., Ahmed, W., Huang, Y., et al. (2016). Grafting: a technique to modify ion accumulation in horticultural crops. Front. Plant Sci. 7:1457. doi: 10.3389/fpls.2016.01457

Nisini, P. T., Colla, G., Granati, E., Temperini, E., Crinó, P., and Saccardo, F. (2002). Rootstock resistance to fusarium wilt and effect on fruit yield and quality of two muskmelon cultivars. Sci. Hortic. 93, 281-288. doi: 10.1016/S0304-4238(01) 00335-1

Niu, M., Huang, Y., Sun, S., Sun, J., Cao, H., Shabala, S., et al. (2018a). Root respiratory burst oxidase homologue-dependent $\mathrm{H} 2 \mathrm{O} 2$ production confers salt tolerance on a grafted cucumber by controlling $\mathrm{Na}+$ exclusion and stomatal closure. J. Exp. Bot. 69, 3465-3476. doi: 10.1093/jxb/erx386

Niu, M., Xie, J., Chen, C., Cao, H., Sun, J., Kong, Q., et al. (2018b). An early ABA-induced stomatal closure, $\mathrm{Na}+$ sequestration in leaf vein and $\mathrm{K}+$ retention in mesophyll confer salt tissue tolerance in Cucurbita species. J. Exp. Bot. 69, 4945-4960. doi: 10.1093/jxb/ery251

Noorden, G. E., Ross, J. J., Reid, J. B., and Mathesius, R. U. (2006). Defective longdistance auxin transport regulation in the Medicago truncatula super numeric nodules mutant. Plant Physiol. 140, 1494-1506. doi: 10.1104/pp.105.075879

Notaguchi, M. (2015). Identification of phloem-mobile mRNA. J. Plant Res. 128, 27-35. doi: 10.1007/s10265-014-0675-6

Notaguchi, M., and Okamoto, S. (2015). Dynamics of long-distance signaling via plant vascular tissues. Front. Plant Sci. 6, 161. doi: 10.3389/fpls.2015.00161

Omid, A., Keilin, T., Glass, A., Leshkowitz, D., and Wolf, S. (2007). Characterization of phloem-sap transcription profile in melon plants. J. Exp. Bot. 58, 3645-3656. doi: 10.1093/jxb/erm214

Ostendorp, A., Pahlow, S., Krüßel, L., Hanhart, P., Garbe, M. Y., and Deke, J. (2017). Functional analysis of Brassica napus phloem protein and ribonucleoprotein complexes. New Phytol. 214, 1188-1197. doi: 10.1111/nph. 14405

Osugi, A., Kojima, M., Takebayashi, Y., Ueda, N., Kiba, T., and Sakakibara, H. (2017). Systemic transport of trans-zeatin and its precursor have differing roles in Arabidopsis shoots. Nat. Plants 3:17112.

Pant, B. D., Buhtz, A., Kehr, J., and Wolf-Rüdiger, S. (2008). MicroRNA399 is a long-distance signal for the regulation of plant phosphate homeostasis. Plant $\mathrm{J}$. 53, 731-738. doi: 10.1111/j.1365-313x.2007.03363.x
Regnault, T., Davière, J. M., Wild, M., Sakvarelidze-Achard, L., Heintz, D., Carrere Bergue, E., et al. (2015). The gibberellin precursor GA12 acts as a long-distance growth signal in Arabidopsis. Nat. Plants 1:15073.

Ren, Y., Xu, Q., Wang, L., Guo, S., Shu, S., Lu, N., et al. (2018). Involvement of metabolic, physiological and hormonal responses in the graft-compatible process of cucumber/pumpkin combinations was revealed through the integrative analysis of mRNA and miRNA expression. Plant Physiol. Biochem. 129, 368-380. doi: 10.1016/j.plaphy.2018.06.021

Rouphael, Y., Cardarelli, M., Rea, E., and Colla, G. (2008). Grafting of cucumber as a means to minimize copper toxicity. Environ. Exp. Bot. 63, 49-58. doi: 10.1016/j.envexpbot.2007.10.015

Ruiz-Medrano, R., Xoconostle-Cázares, B., and Lucas, W. J. (1999). Phloem long-distance transport of CmNACP mRNA: implications for supracellular regulation in plants. Development 126, 4405-4419.

Savvas, D., Colla, G., Rouphael, Y., and Schwarz, D. (2010a). Amelioration of heavy metal and nutrient stress in fruit vegetables by grafting. Sci. Hortic. 127, 156-161. doi: 10.1016/j.scienta.2010.09.011

Savvas, D., Savva, A., Ntatsi, G., Ropokis, A., Karapanos, I., and Krumbein, A. (2010b). Effects of three commercial rootstocks on mineral nutrition, fruit yield, and quality of salinized tomato. J. Plant Nutr. Soil Sci. 174, 154-162. doi: 10.1002/jpln.201000099

Serrano, R., and Gaxiola, R. (1994). Microbial models and salt stress tolerance in plants. Crit. Rev. Plant Sci. 13, 121-138. doi: 10.1080/07352689409701911

Shabala, S. (2003). Regulation of potassium transport in leaves: from molecular to tissue level. Ann. Bot. 92, 627-634. doi: 10.1093/aob/mcg191

Si, Y., Dane, F., Rashotte, A., Kang, K., and Singh, N. K. (2010). Cloning and expression analysis of the Ccrboh gene encoding respiratory burst oxidase in Citrullus colocynthis and grafting onto Citrullus lanatus (watermelon). J. Exp. Bot. 61, 1635-1642. doi: 10.1093/jxb/erq031

Spiegelman, Z., Ham, B. K., Zhang, Z., Toal, T. W., Brady, S. M., Zheng, Y., et al. (2015). A tomato phloem-mobile protein regulates the shoot-to-root ratio by mediating the auxin response in distant organs. Plant J. 83, 853-863. doi: $10.1111 /$ tpj. 12932

Sun, H., Tao, J., Liu, S., Huang, S., Chen, S., Xie, X., et al. (2014). Strigolactones are involved in phosphate- and nitrate-deficiency-induced root development and auxin transport in rice. J. Exp. Bot. 65, 6735-6746. doi: 10.1093/jxb/eru029

Sun, J., Xu, Y., Ye, S., Jiang, H., Chen, Q., and Liu, F. (2009). Arabidopsis ASA1 is important for jasmonate-mediated regulation of auxin biosynthesis and transport during lateral root formation. Plant Cell 21, 1495-1511. doi: 10.1105/ tpc. 108.064303

Sunkar, R., Kapoor, A., and Zhu, J. (2006). Posttranscriptional induction of two $\mathrm{Cu} / \mathrm{Zn}$ superoxide dismutase genes in Arabidopsis is mediated by downregulation of miR398 and important for oxidative stress tolerance. Plant Cell 18, 2051-2065. doi: 10.1105/tpc.106.041673

Thakur, S., Singh, L., Wahid, Z. A., Siddiqui, M. F., Atnaw, S. M., and Din, M. F. M. (2016). Plant-driven removal of heavy metals from soil: uptake, translocation, tolerance mechanism, challenges, and future perspectives. Environ. Monit. Assess. 188, 188-206.

Thieme, C. J., Rojas-Triana, M., Stecyk, E., Schudoma, C., Zhang, W., Yang, L., et al. (2015). Endogenous Arabidopsis messenger RNAs transported to distant tissues. Nat. Plants 1:15025. doi: 10.1038/nplants.2015.25

Tiedemann, R., and Carstens-Behrens, U. (1994). Influence of grafting on the phloem protein patterns in Cucurbitaceae. I. Additional phloem exudate in Cucumis sativus grafted on two Cucurbita species. J. Plant Physiol. 143, 189194. doi: 10.1016/s0176-1617(11)81685-8

Turnbull, C. G. N. (2010). "Grafting as a research tool," in Plant Developmental Biology (Methods and Protocols), eds L. Hennig and C. Köhler (Totowa, N.J: Humana Press), 11-26. doi: 10.1007/978-1-60761-765-5_2

Wang, J., Jiang, L., and Wu, R. (2017). Plant grafting: how genetic exchange promotes vascular reconnection. New Phytol. 214, 56-65. doi: 10.1111/nph. 14383

Wang, Q., Men, L., Gao, L., and Tian, Y. (2017). Effect of grafting and gypsum application on cucumber (Cucumis sativus L.) growth under saline water irrigation. Agric. Water Manag. 188, 79-90. doi: 10.1016/j.agwat.2017.04.003

Warschefsky, E. J., Klein, L. L., Frank, M. H., Chitwood, D. H., and Miller, A. J. (2016). Rootstocks: diversity, domestication, and impacts on shoot phenotypes. Trends Plant Sci. 21, 418-437. doi: 10.1016/j.tplants.2015.11.008 
Wu, R., Wang, X., Lin, Y., Ma, Y., Liu, G., Yu, X., et al. (2013). InterSpecies Grafting caused extensive and hritable alterations of DNA methylation in Solanaceae plants. PLoS One 8:e61995. doi: 10.1371/journal.pone.006 1995 doi: 10.1371/journal.pone.0061995

Xoconostle-Cázares, B., Xiang, Y., Ruiz-Medrano, R., Wang, H., Monzer, J., Yoo, B. C., et al. (1999). Plant paralog to viral movement protein that potentiates transport of mRNA into the phloem. Science 283, 94-98. doi: 10.1126/science. 283.5398.94

Xu, J., Zhang, M., Liu, G., Yang, X., and Hou, X. (2016). Comparative transcriptome profiling of chilling stress responsiveness in grafted watermelon seedlings. Plant Physiol. Biochem. 109, 561-570. doi: 10.1016/j.plaphy.2016. 11.002

Xu, Y., Yuan, Y., Du, N., Wang, Y., Shu, S., Sun, J., et al. (2018). Proteomic analysis of heat stress resistance of cucumber leaves when grafted onto Momordica rootstock. Hortic. Res. 5:53.

Yang, L., Perrera, V., Saplaoura, E., Apelt, F., Bahinm, M., Kramdi, A., et al. (2019). m5C methylation guides systemic transport of messenger RNA over graft junctions in plants. Curr. Biol. 29, 1-12.

Yoo, B. C., Kragler, F., Varkonyi-Gasic, E., Haywood, V., Archer-Evans, S., Lee, Y. M., et al. (2004). A systemic small RNA signaling system in plants. Plant Cell 16, 1979-2000.

Yu, C., Dong, W., Zhan, Y., Huang, Z., Li, Z., Kim, I., et al. (2017). Genomewide identification and expression analysis of ClLAX, ClPIN and ClABCB genes families in Citrullus lanatus under various abiotic stresses and grafting. BMC Genet. 18:33.

Zhang, H., Yu, P., Zhao, J., Jiang, H., Wang, H., Zhu, Y., et al. (2018). Expression of tomato prosystemin gene in Arabidopsis reveals systemic translocation of its mRNA and confers necrotrophic fungal resistance. New Phytol. 217, 799-812. doi: $10.1111 / \mathrm{nph} .14858$

Zhang, K., Novak, O. R., Wei, Z., Gou, M., Zhang, X., Yu, Y., et al. (2014). Arabidopsis ABCG14 protein controls the acropetal translocation of rootsynthesized cytokinins. Nat. Commun. 5:3274.

Zhang, S., Sun, L., and Kragler, F. (2009). The phloem-delivered RNA pool contains small noncoding RNAs and interferes with translation. Plant Physiol. 150, 378-387. doi: 10.1104/pp.108.134767
Zhang, W., Kollwig, G., Stecyk, E., Apelt, F., Dirk, R., and Kragler, F. (2014). Grafttransmissible movement of inverted-repeat-induced siRNA signals into flowers. Plant J. 80, 106-121. doi: 10.1111/tpj.12622

Zhang, W., Thieme, C. J., Kollwig, G., Apelt, F., Yang, L., Winter, N., et al. (2016). tRNA-related sequences trigger systemic mRNA transport in plants. Plant Cell 28, 1237-1249. doi: 10.1105/tpc.15.01056

Zhang, Z., Zheng, Y., Ham, B.-K., Chen, J., Yoshida, A., Kochian, L. V., et al. (2016). Vascular-mediated signaling involved in early phosphate stress response in plants. Nat. Plants 2:16033.

Zhao, L., Liu, A., Song, T., Jin, Y., Xu, X., Gao, Y., et al. (2018). Transcriptome analysis reveals the effects of grafting on sugar and $\alpha$-linolenic acid metabolisms in fruits of cucumber with two different rootstocks. Plant Physiol. Biochem. 130, 289-302. doi: 10.1016/j.plaphy.2018.07.008

Zhao, Y., Xing, L., Wang, X., Hou, Y., Gao, J., Wang, P., et al. (2014). The ABA receptor PYL8 promotes lateral root growth by enhancing MYB77dependent transcription of auxinresponsive genes. Sci. Signal. 7:ra53. doi: 10 1126/scisignal.2005051

Zhong, X., Tao, X., Stombaugh, J., Leontis, N., and Ding, B. (2007). Tertiary structure and function of an RNA motif required for plant vascular entry to initiate systemic trafficking. EMBO J. 26, 3836-3846.

Zhou, Y., Huang, L., Zhang, Y., Shi, K., Yu, J., and Nogués, S. (2007). Chill-induced decrease in capacity of RuBP carboxylation and associated H2O2 accumulation in cucumber leaves are alleviated by grafting onto figleaf gourd. Ann. Bot. 100, 839-848. doi: 10.1093/aob/mcm181

Conflict of Interest: The authors declare that the research was conducted in the absence of any commercial or financial relationships that could be construed as a potential conflict of interest.

Copyright (c) $2020 \mathrm{Lu}$, Liu, Wang, Zhang, Li and Zhang. This is an open-access article distributed under the terms of the Creative Commons Attribution License (CC BY). The use, distribution or reproduction in other forums is permitted, provided the original author(s) and the copyright owner(s) are credited and that the original publication in this journal is cited, in accordance with accepted academic practice. No use, distribution or reproduction is permitted which does not comply with these terms. 